Ed Tan \& Valentijn Visch

\title{
Kijken naar animatie. Tussen herkennen van werkelijkheid en toeschrijven van komedie
}

Het is altijd een vreemde gewaarwording dat kijken naar animatiefilms dezelfde soort inleving kan oproepen als live-action films. Net als bij live-action films kun je als kijker door animatiefilms aan het huilen en lachen gemaakt worden, vind je bepaalde karakters sympathiek, andere onsympathiek, denk je te weten wat de karakters van plan zijn en hoe daarop gereageerd gaat worden door de andere karakters. En dat allemaal doordat je platte tekeningentjes ziet die in beweging zijn gebracht. Op een of andere manier creëren ze de indruk van bewegingen van voorwerpen en van ruimte, diepte en tijd. Het meest wonderlijke is dat animatiefilms getekende poppetjes en gefotografeerde voorwerpen tot leven wekken, het worden mensachtige wezens die emoties hebben en met elkaar omgaan, ongeveer zoals wij dat in werkelijkheid doen. De animatiefilm schept een complete sociale werkelijkheid.

Misschien wordt het minder vreemd dat we ons kunnen inleven in de wereld die animaties ons voorschotelen, als je bedenkt dat we dat ook al doen in LA (life action) film terwijl we weten dat de karakters gekostumeerde acteurs zijn, de huiskamers in studio's staan, de secondes altijd anders tikken en de pistolen nooit met scherp geladen zijn. Niettemin vinden we films vaak 'realistisch' en 'geloofwaardig'. Blijkbaar kunnen we de in film en animatie opgeroepen werelden dus op dezelfde manier bekijken als de werkelijkheid. In dit artikel zullen we eerst de focus wat breder instellen door in te gaan op de relatie tussen kunst en werkelijkheid. Kunst zal beschreven worden als een interessante afwijking van de dagelijkse werkelijkheid, onderhevig

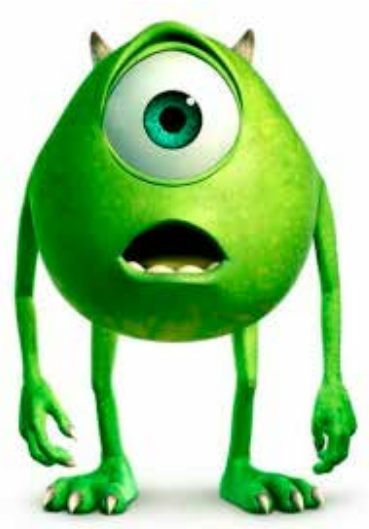
aan zeer bepaalde herkenningsvoorwaarden. In het tweede deel van dit artikel zal worden ingegaan op de psychologie van het 'herkennen' en 'toeschrijven' van emoties aan stimuli uit de werkelijkheid. In het laatste deel zal tenslotte worden gekeken naar de consequenties van herkennings- en toeschrijvingsmechanismen voor het kijken naar en maken van animatiefilm. 


\section{Kunst en werkelijkheid}

Het is moeilijk denkbaar dat allerlei gedrag in de werkelijkheid plaatsvindt zonder enige vorm van betekenistoeschrijving. We hebben van onze geboorte af aan geleerd om aan gebeurtenissen om ons heen betekenis te hechten, oorzaken te identificeren en mogelijke gevolgen te voorzien. Een lekke fietsband (gebeurtenis-betekenis) impliceert dat de lucht eruit is gelopen (gevolg-betekenis) en kan zijn gebeurd doordat je door iets scherps bent gereden (oorzaak-betekenis). Je kunt de band repareren (toekomstige gebeurtenis) door hem te plakken. Behalve dat we betekenissen, oorzaken en gevolgen herkennen in de gebeurtenissen om ons heen, beïnvloeden de gebeurtenissen ook onze emoties. Een lekke band zal er bijvoorbeeld bij veel mensen voor zorgen dat zij zich boos of gefrustreerd voelen. Natuurlijk is de emotionele beoordeling van situaties afhankelijk van de aard van de gebeurtenis en van de aard van de beoordelende persoon. Bij lekke banden raak je gefrustreerd omdat een futiele zaak het je onmogelijk maakt je weg te vervolgen, en veel meer emotionele beoordelingen en reacties zijn er niet. Maar als we films of honden als object van emotie nemen, blijkt dat daarover sterk uiteenlopende emoties kunnen ontstaan (hondenliefhebbers tegenover hondenhaters).

Omdat we zo goed betekenissen kunnen verlenen aan gebeurtenissen om ons heen, is dit toeschrijvingsproces precies wat kunst gebruikt, of beter, uitbuit. Om te zorgen dat kijkers betekenissen toeschrijven zal de kunstenaar er altijd voor zorgen dat er een relatie met de werkelijk in stand wordt gehouden, maar die kan al naar gelang de wensen van de kunstenaar gemakkelijk (bijvoorbeeld in realistische kunst) of moeilijk (bijvoorbeeld in abstracte kunst) te vinden zijn voor de beschouwer. Een minimale relatie met de werkelijkheid lijkt voor kunst onontkoombaar. Ieder kunstwerk is namelijk per definitie onderdeel van de werkelijkheid - al is het alleen maar door de tijd en plaats die het inneemt of door de gebruikte materialen en vormen. Daarnaast imiteren kunstwerken vaak ook delen van werkelijkheid. De toeschouwer heeft hierdoor altijd een minimum aan herkenningspunten om vervolgens betekenissen toe te schrijven.

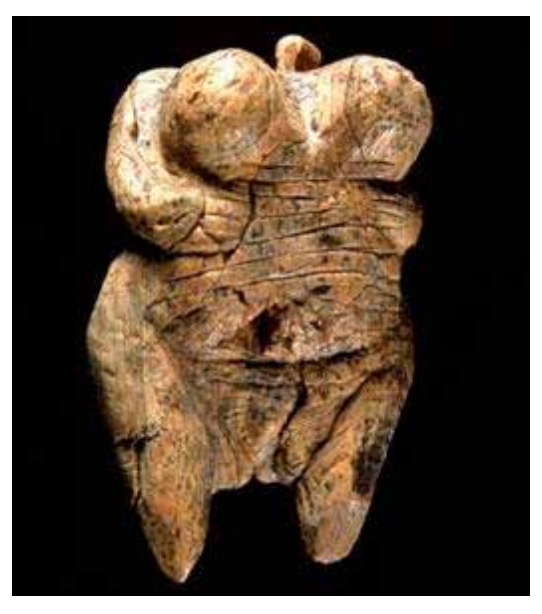

Figuur 2. Venusbeeldje

Bron: N.J. Conard, 'A female figurine from the basal Aurignacian of Hohle Fels Cave in southwestern Germany', Nature, 459 (2009) 248-252 
Kunstwerken zullen echter nooit alleen maar de werkelijkheid imiteren als een spiegel - volledige imitatie is zelfs onmogelijk - maar altijd een selectie van de werkelijkheid imiteren en daaraan het nodige toevoegen en veranderen. Uit deze transformatie van de geïmiteerde elementen kan vaak de bedoeling van de kunstenaar worden opgemaakt. Een mooi voorbeeld is het oudste gevonden beeld, het Venusbeeldje van 35.000 v.Chr. in figuur 2. Het stelt een vrouw voor met enorme borsten en geslachtsdeel. De imitatie van vrouwen en mensfiguren zorgt voor herkenning, terwijl het getransformeerde formaat van de lichaamsdelen de kunstenaarsintentie laat zien, of althans onze interpretatie over de betekenis stuurt (bijvoorbeeld 'vruchtbaarheidssymbool').

Terugkerend naar de processen die zich in de beschouwer afspelen, noemen we de identificatie van geïmiteerde fragmenten van de werkelijkheid in kunst herkenning. Bijvoorbeeld van de mensfiguur in het Venusbeeld uit figuur 2, van vogelzangritmiek in de muziek van Messiaen of de wanhoop van de karakters in Von Triers MELANCHoliA (20II). Een voorwaarde van herkenning is dat er een imitatieproces tussen het kunstwerk en de werkelijkheid heeft plaatsgevonden: het kunstwerk bevat herkenbare imitaties van delen uit de werkelijkheid - dit kan variëren van mensen tot geluiden tot bewegingen. Toeschrijven daarentegen noemen we het geven van betekenis aan de getransformeerde elementen die deel uitmaken van het kunstwerk. Betekenistoekenning of kortweg toeschrijving houdt in dat een directe verbinding door imitatie met de werkelijkheid ontbreekt, waardoor alleen herkenning onmogelijk is. De vruchtbaarheidssymboliek in het beeldje, de rust in de muziek van Messiaen, of het noodlot in MELANCHOLIA zijn het resultaat van toeschrijving, niet van herkenning. Zoals herkenning imitatie van de werkelijkheid nodig heeft, zo berust toeschrijving op transformatie ervan. Vaak zijn de toegeschreven betekenissen interessanter dan de herkenningen omdat de toeschrijving associatieve en metaforische betekenissen omvat terwijl herkenning vaak veel eenvoudiger is. In deze paper willen we echter aantonen dat toeschrijving vrijwel altijd vooraf gegaan wordt door herkenning: je herkent eerst een deel van het kunstwerk waarna je op basis daarvan een complexere toeschrijving kunt maken.

Voor de beschouwer is het onderscheid tussen herkennen en toeschrijven niet altijd even makkelijk vast te stellen. Een opname van een persoon in een live-action film wordt door de beschouwer gezien als een volledige gelijkende imitatie van de persoon voor de camera, waarbij wel in acht wordt genomen dat het om een fotografische opname gaat. Het gebruik van sterk vertekenende objectieven in dezelfde opname zou evenwel tot waarneming van een transformatie leiden. Tussen de canonische weergave van de persoon met behulp van standaardlenzen en de sterk vertekende zitten allerlei gradaties. In functionele afbeeldingen zoals die welke voor instructie of uitleg van een onderwerp zijn bedoeld, is meestal wel duidelijk wanneer sprake is van imitatie, en wanneer van transformatie. Het laatste kan het geval zijn om zo bepaalde details door benadrukking beter inzichtelijk te maken. Bij de interpretatie van kunstwerken wisselen de herkennings- en toeschrijvingsprocessen elkaar echter permanent af, zonder dat het de beschouwer precies duidelijk is wanneer er herkend en wanneer er toegekend wordt. Om die duidelijkheid te krijgen is analytische studie 
nodig. Als je vogelritmes op pianomuziek zet, is de ritmiek geïmiteerd, maar zijn de tonen getransformeerd. Een complicatie daarbij is dat ritmiek niet zonder toonwaarneming te beluisteren is. In MELANCHOLIA zijn de emoties geïmiteerd door de acteurs, maar binnen een verhaal dat een sterk getransformeerde versie is van de werkelijkheid, en in het Venusbeeldje is de figuur geïmiteerd maar zijn bepaalde lichaamsdelen getransformeerd. Toekenning en herkenning in kunstwaarneming zijn in de praktijk niet te scheiden door hun onderlinge afhankelijkheid in het werk. Niettemin is de balans tussen deze twee processen fundamenteel voor betekenisvorming.

In het vervolg van dit artikel zullen wij de stelling uitwerken dat animatie een middel bij uitstek is om toeschrijving te sturen. Animatie betekent letterlijk 'van leven voorzien' door middel van beweging of in de woorden van Holloway uit I972: 'To give life and soul to a design, not through the copying but through the transformation of reality.${ }^{\mathrm{I}}$ Om te weten welke transformaties nodig zijn voor effectieve toeschrijving van 'leven' en 'emoties' moeten we eerst weten hoe het herkenning en toeschrijving werkt in de psychologie van bewegingswaarneming.

\section{Herkennen en toeschrijven in psychologie}

In dit gedeelte zullen we ons vooral richten op het herkennen van emotie door het zien van bewegingen. Grappig genoeg maken experimentele onderzoeken naar bewegingswaarneming meestal gebruik van bewegende beelden getoond op een scherm, vanwege de eis van standaardisatie van testprocedures. De resultaten zeggen daardoor misschien in de eerste plaats iets over herkenning en toeschrijving van betekenis in gefilmde gebeurtenissen, en pas in tweede instantie iets over waarneming van scènes in de werkelijke wereld. Bewegingsperceptie-onderzoek richt zich veelal op het identificeren van zgn. 'cues' of aanwijzingen in bewegingen die zorgen voor een bepaalde herkenning of toeschrijving. Bewegingen blijken hele sterke visuele cues te bevatten voor de herkenning van betekenis in gebeurtenissen. We kunnen bijvoorbeeld gemakkelijk het gender van iemand herkennen aan haar of zijn loopbewegingen. ${ }^{2}$ Deze herkenning is zelfs te automatiseren; het gender van lopende personen kan betrouwbaar door een computerprogramma worden herkend. ${ }^{3}$

Wanneer je geëmotioneerd bent, wil je iets veranderen aan de huidige situatie met inzet van je lichaam. ${ }^{4}$ Als je droevig bent trek je je bijvoorbeeld terug en als je blij bent wil je dat vooral delen met alles om je heen, wat zorgt voor grote bewegingen naar buiten toe. De drang om iets te veranderen in je relatie met de omgeving is volgens veel emotie-onderzoekers zelfs een van de essenties van emotie. Uit dat inzicht volgt dat emoties zich verraden door neigingen om een of andere actie uit te voeren. Onderzoek laat zien dat herkenning van emoties op basis van de lichaamsbewegingen die iemand maakt heel succesvol is. ${ }^{5}$

Bewegingen lijken zoveel cues te bevatten voor emoties, dat de waarnemer de vormen van de lichaamsdelen die in beweging zijn nauwelijks hoeft te zien om acties en emotionele actieneigingen te herkennen. Pure beweging lijkt voldoende. In een beroemd onderzoek heeft Johansson (I973) bij een acteur twaalf reflecterende schijf- 
jes aan zijn gewrichten bevestigd en de acteur verschillende handelingen laten voordoen zoals rennen, lopen en dansen. ${ }^{6}$ Met een speciale camera werden alleen de reflecterende schijfjes opgenomen. Het bleek dat proefpersonen door het zien van die beperkte set bewegende punten moeiteloos de acteur en zijn activiteiten konden herkennen. Dit motion-capture experiment toont aan dat in menselijke beweging erg veel informatie besloten ligt, en heeft verschillende onderzoekers geïnspireerd om op een meer structurele manier te kijken naar de informatie die uit bewegingen te halen is. Zo is op basis van de twaalf bewegende punten te zien wat het geslacht is van de beweger,7 welke emoties worden uitgedrukt ${ }^{8}$ en zelfs of er misleidende intenties worden geuit. ${ }^{9}$ De informatierijkdom van biologische bewegingen heeft ook animators verleid om filmbeelden als basis te gebruiken en daar overheen te animeren - de zgn. Rotoscoop. Voorbeelden hiervan zijn de Betty Boop films uit de jaren dertig, de recente Kuifje film (HET GEHEIM VAN DE EENHOORN, 2OII) en natuurlijk de films van Gerrit van Dijk JANNEKE (I990), I MOVE SO I AM (I997), en THE LAST WORDS OF DUCTH SCHULTZ (2003).

Omdat op deze manier de realiteit niet alleen wordt geïmiteerd, of beter gezegd wordt opgenomen, maar ook wordt geabstraheerd tot een beperkte set van bewegende punten, kun je je afvragen of de proefpersonen emoties herkennen of toeschrijven. In een recent experiment (submitted) hebben we geprobeerd imitatie over te laten gaan in transformatie om te zien of en op welk punt herkenning overgaat in toeschrijving. Een belangrijk onderscheid tussen herkenning en toeschrijving van emoties is dat voor herkenning altijd een emotie-expressie nodig is die als juist of onjuist herkend kan worden. Voor toeschrijving is geen expressie aanwezig en daarom is het niet objectief vast te stellen of de toegeschreven emotie juist of onjuist is. In ons experiment drukten acteurs voor de camera met gezicht en lichaam verschillende emoties uit. Bij de uitdrukking van de gekozen emoties voor dit experiment komen relatief grote bewegingen kijken (woede, grote vreugde, grote angst, wanhoop). Aan proefpersonen werd gevraagd welke emoties uitgebeeld werden en hoe sterk iedere emotie werd uitgedrukt. De proefpersonen kregen de emotie-expressies echter niet alleen als 'normale' videorepresentatie te zien, maar ook in sterk getransformeerde vorm. De frames van de filmopnamen werden zo bewerkt dat de vormen van gezicht en lichaam in stappen vervaagden, zodat in de meest vervaagde versie alleen een globaal bewegingspatroon overbleef. Uit de resultaten van het experiment bleek dat herkenning van woede veel beter bestand was tegen videoabstractie dan de andere drie emoties. Interessant aan dit experiment is dat we niet alleen konden zien welke stimuli juist herkend werden, maar ook welke fout herkend werden. Foute herkenning is, als deze systematische vormen aanneemt, te beschouwen als toeschrijving. Zoals verwacht werden er vaker onjuiste emoties toegeschreven naarmate de informatie in het beeld verminderde en opnieuw werd met name woede (foutief) toegeschreven. Deze studie illustreert dat vanuit het gezichtspunt van de onderzoeker wel is vast te stellen waar herkenning overgaat in toeschrijving - namelijk bij foutieve herkenning. Voor de kijker kan herkenning echter vloeiend overgaan in toeschrijving wanneer hij of zij zich niet bewust is van een foutieve herkenning. Wanneer de kijker echter sterk twijfelt aan de herkende emotie, zou zij zich kunnen realiseren dat zij misschien aan 
het toeschrijven is - hoewel het nog altijd een moeizame herkenning zou kunnen zijn. Bij animatiefilm is het gepresenteerde materiaal meestal niet opgenomen uit de werkelijkheid maar worden delen uit de werkelijkheid op een indirectere manier gepresenteerd, bijvoorbeeld getekend. Hierdoor kan het voor de kijker heel moeilijk zijn om te bepalen of er een juiste betekenisherkenning mogelijk is. Eigenlijk is de animatiekijker altijd toeschrijvend, ook al kan de animatiefilm de indruk wekken dat er herkend wordt.
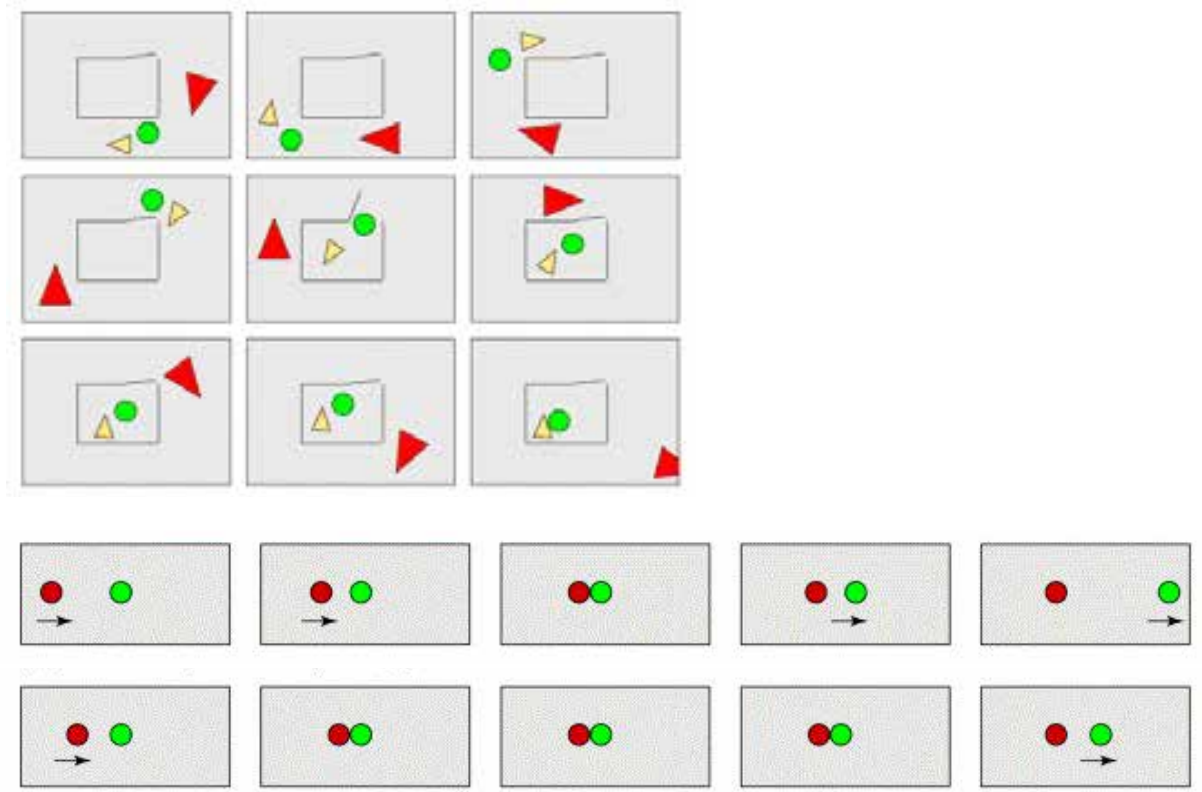

Figuur 3. Bron: Scholl \& Tremoulet (2000); geschematiseerde stills uit de animatie van Heider en Simmer (1944) (bovenste figuur) en uit animatie van Michotte (1963) (onderste twee figuren). ${ }^{10}$

Net als naar het herkennen van betekenis door het zien van bewegingen, is er veel experimenteel onderzoek gedaan naar betekenistoeschrijving. Dit toeschrijvingsonderzoek is met name interessant voor animatie, omdat er nu geen beelden uit de werkelijkheid worden genomen, maar deze worden gecreëerd. Wanneer je weet welke bewegingen voor welke toeschrijvingen zorgen zou je in theorie een computer een animatie kunnen laten maken. Het eerste onderzoek op dit terrein is gedaan door Heider en Simmel die een zeer minimale animatie (zie figuur 3) lieten zien en proefpersonen vervolgens lieten beschrijven wat er gebeurde. ${ }^{\text {II }}$ Het bleek dat de proefpersonen allerlei eigenschappen aan de bewegende vormen toekenden. Zij werden als figuren gezien die levend waren, emoties en doelen hadden en intenties. Kortom, aan een simpele animatie werden complete verhalen toegeschreven. Dit experiment heeft een hele serie onderzoekers geïnspireerd tot vervolgonderzoek waarin op een meer structurele manier onderzocht werd welke aspecten van een beweging nu precies voor welke toeschrijving zorgen. Dit meer structurele onderzoek is in 1946 gestart door Michotte die het toeschrijven van causaliteit onderzocht. Net als Heider 
en Simmel liet hij een eenvoudige animatie zien (zie figuur 3) en vroeg hij proefpersonen te beschrijven wat er gebeurde - echter met als belangrijk verschil dat hij in de animaties steeds één bewegingscue varieerde waardoor het effect van die cue op de toeschrijvingvormen duidelijk werd. De animatie bestond uit een rode cirkel die steeds van links het beeld inkomt, met constante snelheid voortbeweegt en tot stilstand komt bij een (stilstaande) groene cirkel in het midden van het beeld. Na het stoppen van de rode cirkel begint de groene cirkel te bewegen. Door nu de pauzetijd te variëren tussen de stop van de rode cirkel en de start van de groene cirkel, bleken de proefpersonen compleet verschillende relaties tussen de cirkels te zien. Bij een pauze van nul seconden (bovenste serie plaatjes) lijkt de groene cirkel weggestoten te worden door de rode cirkel. Bij een langere pauzetijd (onderste serie plaatjes) lijkt het alsof de groene cirkel uit eigen beweging weggaat. Bovendien wordt het groene cirkeltje dan opeens gezien als een intentioneel wezen.

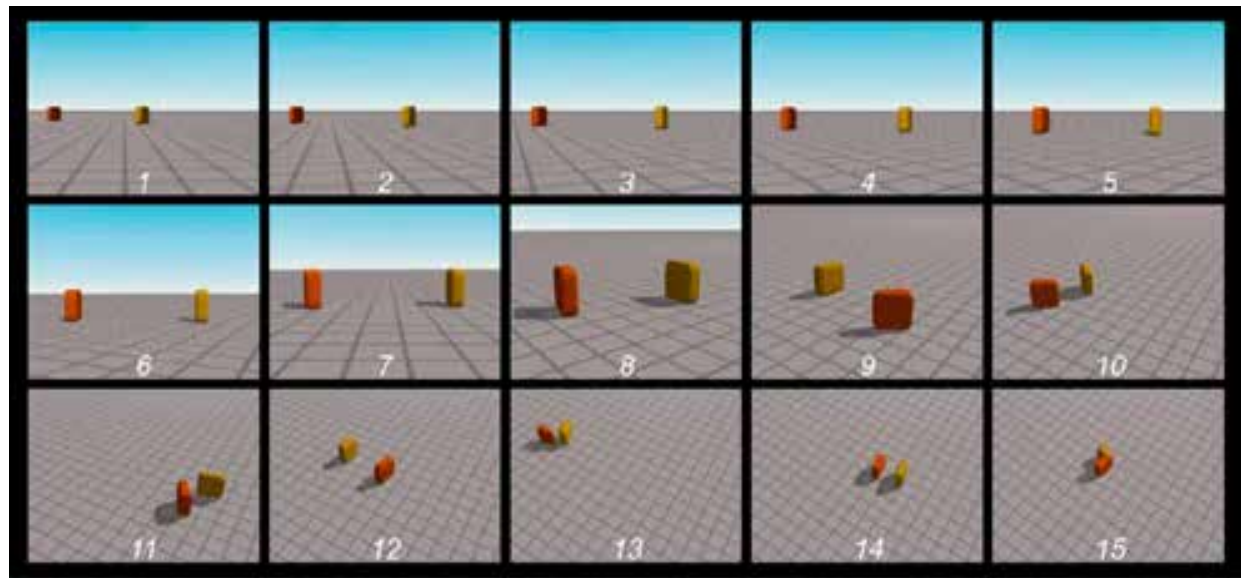

Figuur 4. Stills uit animatie Visch \& Tan (2009) $)^{12}$

In de animatiewereld is het natuurlijk al langer bekend dat bewegingen en timing essentieel zijn voor het toeschrijven van een specifieke betekenis. In eerder onderzoek hebben we proberen uit te zoeken wat voor effect het type beweging heeft op toeschrijving. ${ }^{13}$ We waren daarbij geïnteresseerd in toeschrijving van emotie, maar vooral in toeschrijving van complexere concepten als filmgenres. Genretoekenning is voor de kijker van groot belang omdat het vormgeeft aan zijn verwachtingen over het verhaal ${ }^{14}$ en over de te verwachten emoties. ${ }^{15}$ Wanneer iemand overreden wordt in een komedie is dat meestal grappig (c.f. de running-gag in NEW KIDS TURBO (20IO)) terwijl dit in een documentaire afgrijzen zou opwekken. Door de geschiedenis heen kun je vier grote genres onderscheiden (non-fictie, komedie, drama, en actie). Deze zijn door Aristoteles in zijn Poetica ${ }^{16}$ al omschreven en vormen de tijdloze basis voor tijdelijke genrecombinaties (zoals het komisch-drama); zie voor verdere genrebeschrijvingen Visch. ${ }^{17} \mathrm{Bij}$ analyse van bewegingen in films uit de vier genres viel het op dat ze vooral verschillen in de eigenschappen snelheid, vloeiendheid, efficiëntie, detaillering en vervorming van beweging. Snelheid combineert plaats en tijd, wat 
de reden is deze te beschouwen als de moeder-variabele van alle bewegingen. De effecten van bewegingssnelheid op emotie en genretoeschrijving zijn dan ook groot. Langzame bewegingen worden als droevig gezien en komen veel in drama voor terwijl snelle bewegingen vooral in hoge arousal emoties voorkomen, ${ }^{18}$ en vaak gebruikt worden in actie en komedie. ${ }^{19}$ Deze regelmatigheden zijn ook in de animatiefilm te vinden. Langzame bewegingen zie je in de droevige animatie zoals in FUGA van Hans Nassenstein (I996), terwijl snelle bewegingen typerend zijn voor actie en comedy, zoals in CARS (Lasseter, 2006). De vloeiendheid van een beweging wordt bepaald door de overgangen tussen twee verschillende snelheden; deze kan abrupt zijn of vloeiend. Abrupte bewegingen komen veel voor bij komedie (voor het verrassingseffect - beroemd voorbeeld is Chuck Jones's ROAD RUNNER (I948)). Vloeiende bewegingen komen daarentegen vooral voor bij drama, tot in de camerabewegingen - zie bijvoorbeeld вамві (I942). Efficiëntie van de beweging wordt bepaald door hoe een object op zijn doel afgaat; neemt hij een efficiënte korte route, bijvoorbeeld een binnenbocht in een achtervolgingsscene, of een inefficiënte lange route, een buitenbocht. Natuurlijk is inefficiëntie vooral zichtbaar in komedie terwijl efficiëntie een kenmerk van actiefilms is. Tenslotte lijken voor genretoeschrijving de detaillering van de beweging en vervorming van het object tijdens de richtingsverandering van belang. In de animatieliteratuur zijn deze eigenschappen bekend als 'elasticiteit' en worden ook wel het principe van 'squash and stretch' genoemd. ${ }^{20}$ Voor ons experiment hebben we een korte animatie gemaakt van twee blokjes die elkaar achtervolgen - zie figuur 4 . De bewegingen van de achtervolger waren op de vijf bewegingsparameters gevarieerd, waarbij we voor ieder bewegingstype vijf niveaus hadden gemaakt, oplopend van heel sterk aan de ene kant van het spectrum via neutraal naar heel sterk aan het andere kant (--, -, o, +, ++). De filmpjes werden aan 52 proefpersonen getoond en het bleek dat zij inderdaad aan veel filmpjes, in overeenstemming met onze verwachtingen, specifieke emoties en genres koppelden. ${ }^{2 \mathrm{I}}$ Voor dit artikel is het echter van groter belang om te kijken hoe de genres zich tot elkaar verhielden. Uit de data bleek dat aan de neutrale animatie (niveau o) vrijwel steeds het label 'non-fictie' werd toegeschreven. Opvallend was dat de mate van afwijking van deze neutrale bewegingen zorgde voor een toeschrijving van een specifiek genre. Aan een animatie met kleine afwijkingen ten opzichte van de neutrale non-fictie bewegingen werd het drama genre toegekend, aan iets sterkere het actie genre en aan hele sterke afwijkingen van non-fictie bewegingen werd het genrelabel komedie toegekend. Dit resultaat is in overeenstemming met bestaande genretheorieën, die overigens behalve in dit experiment nooit empirisch getoetst zijn. In die theorieën wordt komedie als parodie op de werkelijkheid gezien $^{22}$ terwijl drama juist veel dichter bij de werkelijkheid staat ${ }^{23}$ - zoals goed te zien is in psychologisch en sociaal drama. Actie zit dan tussen drama en komedie in, wanneer de genres geordend zijn naar gelang hun afwijking ten opzichte van non-fictie. In termen van transformatie betekent het dat het genre komedie bij de grootste transformatie van de werkelijkheid wordt toegekend en drama bij de kleinste - met uitzondering van non-fictie zelf. Bij deze conclusie moet wel worden aangemerkt dat zij is gebaseerd op onderzoek naar bewegingscues. Ze is (nog) niet onderzocht voor andere cues (zoals bijvoorbeeld vormen of intenties). 


\section{Herkennen en toeschrijven in animatie}

Wanneer de kijker een genre toekent aan een film lijkt hij zijn genrekeuze te baseren op de mate van afwijking, of transformatie, van het getoonde ten opzichte van de werkelijkheid: is er geen afwijking, dan zal de kijker betekenissen herkennen, is die er wel dan zal hij toeschrijven. De kijker ervaart de mate van afwijking waarschijnlijk niet bewust; als een acteur goed acteert, zal de kijker meeleven en het gevoel hebben dat hij de intenties en de emotionele reacties van de acteur herkent. Bovenstaande geldt vooral voor live action film. De kijker zal eerst gedeeltelijke imitaties van werkelijkheid zien op het beeld (mensen en omgevingen) en in eerste instantie het non-fictie genre toeschrijven. Vervolgens zal hij, om zijn verwachtingen af te stemmen, zich ervan willen verzekeren dat het toegeschreven non-fictie genre het juiste is en op zoek gaan naar transformaties - 'Bewegen en handelen de mensen in het beeld wel of niet zoals in de werkelijkheid?’. Op basis van de grootte van de transformaties wordt vervolgens het genre aangepast. Wanneer een fictiegenre wordt toegeschreven aan de film, zal de kijker zich ervan bewust zijn dat veel van de betekenissen die hij aan de film toeschrijft niet dezelfde zijn als die welke hij aan de realiteit zal toeschrijven. De kijker zal net doen of een pistool in een fictiefilm met scherp geladen is terwijl hij weet dat dit niet zo is vanwege de fictie categorisatie. De kijker zal zich echter niet altijd bewust willen zijn van toeschrijvingsprocessen, maar omwille van het plezier van het inleven doen alsofhij herkent en alsof hij de getoonde wereld als werkelijkheid ziet.

Het grote verschil tussen animatie en live action is voor de kijker dat hij bij animatie veel minder herkenningspunten tot zijn beschikking heeft om het toeschrijvingsproces op gang te brengen. Dit heeft tot gevolg dat de kijker van animatie zijn genrekeuze in eerste instantie baseert op de getoonde afwijkingen van de werkelijkheid waardoor hij de animatie als komisch classificeert. Vervolgens zal de kijker evalueren of dit het juiste genre is, door niet te kijken naar de afwijking van de werkelijkheid maar naar de overeenstemming met de werkelijkheid. Wanneer er bijvoorbeeld veel realistisch ogend pijn of leed wordt getoond kan genretoeschrijving verschuiven richting actie, drama of non-fictie. Na het vaststellen van het genre, kan de kijker net als bij non-fictie betekenissen gaan toeschrijven en zich inleven door te doen alsof hij herkent.

Het eerst toegeschreven genre verschilt dus bij live-action en animatie. Live-action zal initieel als non-fictie worden gezien en animatie als komedie. Vervolgens zal de afwijking, respectievelijk overeenstemming, van het getoonde met de werkelijkheid bepalen in welk genre het getoonde wordt gecategoriseerd. Anders gezegd: het is voor de animator even moeilijk om drama te maken als voor de live-action regisseur om een komedie te maken. Toch telt het live-action repertoire wel degelijk vele komedies, dus het wachten is op animatie-drama. Het lijkt erop dat animatoren de achterstand gaan inhalen, getuige bijvoorbeeld het succes van titels als WALTZ WITH BASHIR (2008) en PERSEPOLIS (2008), titels die niet alleen geroemd worden om hun dramatische kwaliteiten maar ook om hun waarde als historische, dat wil zeggen nonfictie documenten. 
In deze bijdrage is geprobeerd inzicht te verschaffen in de effecten van de relatie van kunst, animatie en live-action films met de werkelijkheid op de betekenisgeving van de kijker. Er werd een onderscheid gemaakt tussen betekenisherkenning en -toeschrijving; in tegenstelling tot toeschrijving vereist herkenning dat het getoonde elementen uit de werkelijkheid bevat. Herkenning fungeert hierbij als katalysator. Uiteindelijk zal de beschouwer vooral geïnteresseerd zijn in toeschrijven omdat dat het meest interessant is. Uit psychologisch onderzoek blijkt dan ook dat mensen spontaan aan zeer eenvoudige animaties een enorme variëteit aan betekenissen toeschrijven (van gender tot emoties tot intenties). Het toeschrijven van genres is fundamenteel voor iedere filmkijker, en uit psychologische experimenten blijkt dat men daarbij uitgaat van de afstand van het getoonde ten opzichte van de werkelijkheid. In die afstand ligt precies het verschil tussen animatie en live-action. Beide vormen geven de kijker de mogelijkheid zich in te leven, maar live-action stuurt de kijker vanuit non-fictie naar fictie, terwijl animatie hem vanuit fictie naar non-fictie stuurt.

\section{Noten}

I Geciteerd in Paul Wells, Understanding animation, Routlegde, London I998.

2 N.F. Troje, 'Decomposing biological motion: a framework for analysis and synthesis of human gait patterns', Journal of Vision, 2(5), 2002, p. 37I-387.

3 M.S. Nixon, J.N. Carter, D. Cunando, P.S. Huang \& S.V. Stevenage, 'Automatic gait recognition', Biometrics, 2002, p. 23I-249.

4 N.H. Frijda, The emotions, Cambridge University Press, New York I986.

5 M. de Meijer, 'The contribution of general features of body movement to the attribution of emotions', Journal of Nonverbal Behavior, I3(4), 1989, p. 247-268.

6 G. Johansson, 'Visual perception of biological motion and a model for its analysis', Perception and Psychophysics, I4(2), I973, p. 20I-II.

7 L.T. Kozlowski \& J.E. Cutting, 'Recognizing the sex of a walker from a dynamic point-light display', Perception Q Psychophysics, 2I, I977, p. 575-580.

8 W.H. Dittrich, T. Troscianko, S.E.G. Lea \& D. Morgan, 'Perception of emotion from dynamic pointlight displays represented in dance', Perception, 25, I996, p. 727-738.

9 S. Runeson \& G. Frykholm, 'Kinematic specification of dynamics as an informational basis for person-and-action perception: Expectation, gender recognition, and deceptive intention', Journal of Experimental Psychology: General, iा2(4), I983, p. 585-615.

Io B.J. Scholl \& P.D. Tremoulet, 'Perceptual causality and animacy. Trends in Cognitive Sciences', 4(8), 2000, p. 299-309; A. Michotte, The perception of causality, Methuen, London I963.

II F. Heider \& M. Simmel, 'An experimental study of apparent behavior', American Journal of Psychology,

57, I944, p. 243-249.

I2 V.T. Visch \& E.S.H. Tan, 'Categorizing moving objects into film genres: The effect of animacy attribution, emotional response, and the deviation from non-fiction', Cognition, ilo (2), 2009, p. 265-272.

I3 Ibidem.

I4 T. Grodal, Moving pictures, Clarendon Press, Oxford I997.

I5 E.S. Tan, Emotion and the structure of narrative film, Erlbaum, Mahwah NJ I996.

I6 Aristoteles, Poëtica (vert. N. van der Ben \& J.M. Bremer), Athenaeum Polak \& Van Gennep, Amsterdam I988 (geschreven 335-323 BC).

I7 V.T. Visch, 'Looking for Genres: The Effect of Film Figure Movement on Genre Recognition', Doctoral Thesis Vrije Universiteit, Amsterdam 2007.

I8 K.R. Scherer \& H. Ellgring, 'Multimodal Expression of Emotion', Emotion, 7(I), 2007, p. I58-I7I.

I9 David Gianetti, Invito al cinema di Michelangelo Antonioni, Mursia, Milano I999. 
20 F. Thomas \& O. Johnston, The illusion of live: Disney animation, Disney Editions, New York I98I.

2I Zie Visch \& Tan, 'Categorizing moving objects into film genres' voor een overzicht. En ook: V.T. Visch,

M. Goudbeek \& M. Mortillaro (submitted), 'Robust anger recognition of segmented and visually impaired dynamic bodily emotion expressions'.

22 G. Mast, The comic mind: Comedy and the movies ( ${ }^{\text {nd }}$ ed.), University of Chicago Press, Chicago 1979.

23 S. Neale, Genre and Hollywood, Routledge, London 2000. 